\title{
Implementation of multiaxial high cycle fatigue criterion in finite element analysis
}

\author{
Quoc Huy Vu, Dinh Quy Vu \\ Department of Aeronautical and Space Engineering, Hanoi University of Science and Technology, Vietnam
}

\begin{abstract}
Multiaxial high cycle fatigue analyses concern many mechanical components in several industries (aircraft, automobile, railway...). Many multiaxial fatigue criteria have been proposed in the literature for metals. This study deals with the integration of fatigue criteria in finite element code by using APDL (ANSYS Parametric Design Language) scripting language. Three criteria have been implemented including Crossland, Dang Van and Vu et al. [6] criteria. The predictions of $\mathrm{Vu}$ et al. criterion are in good accordance with the experimental data.
\end{abstract}

\section{Introduction}

Mechanical components in service are usually subjected to multiaxial complex loading and their required lifetimes are often in the range of high cycle fatigue $\left(10^{6}-10^{9}\right.$ cycles). In order to determine the stress level allowable for the safety of the component, many multiaxial fatigue endurance criteria have been proposed in the literature for metals $[1,2]$. For application with real structure, the multiaxial fatigue criteria need to be implemented with finite element codes [3]. Obvious advantages of this approach: benefit the material properties data, 3D design of structure, meshing, setup of load and boundary conditions, stress analysis by finite element method and result post-processing. The finite element analysis programs allow using the stress analysis results for fatigue analysis. Many commercial CAE (ComputerAided Engineering) softwares now provide the capability of fatigue analysis such as ANSYS, nCode, Msc Fatigue, Abaqus, Samcef... However, only limited softwares integrate the multiaxial fatigue criteria such as nCode (integration of Dang Van criterion), Samcef (integration of Crossland criterion).

\section{Multiaxial high cycle fatigue criteria}

From the point of view of numerical implementation, the most convenient are two categories: criteria based on stress invariants and criteria using critical plane approaches. Two classical criteria widely used are Crossland criterion [4] (invariant group) and Dang Van criterion [5] (critical plane group).

\subsection{Crossland criterion}

Crossland proposed a combination between the amplitude of the second invariant of the stress deviator $\left(J_{2, a}\right)$ and the maximum hydrostatic stress $\left(\sigma_{H, \text { max }}\right)$ :

$$
\sqrt{J_{2, a}}+\alpha \sigma_{H, \max } \leq \beta
$$

where $\alpha$ and $\beta$ are material parameters. In case of out-ofphase bending, the value of $J_{2, a}$ can be defined as a function of macroscopic stress components:

$$
\sqrt{J_{2, a}}=\frac{1}{\sqrt{2}} \sqrt{\left(\frac{\sigma_{a}^{2}}{3}+\tau_{a}^{2}\right)+\sqrt{\left(\frac{\sigma_{a}^{2}}{3}+\tau_{a}^{2}\right)^{2}-\frac{4}{3} \sigma_{a}^{2} \tau_{a}^{2} \sin ^{2} \delta}}
$$

where $\delta$ is the phase shift angle between normal and shear stress.

\subsection{Dang Van criterion}

Dang Van proposed a combination of local shear stress $\tau(t)$ and the hydrostatic stress $\sigma_{H}(t)$ that looks for the maximal value in all grain orientations and in variable time. The simplified form of the Dang Van criterion can be formulated as:

$$
\max _{t}\left[\tau(t)+\alpha \cdot \sigma_{H}(t)\right] \leq \beta
$$

where $\alpha$ and $\beta$ are material parameters.

\section{$2.3 \mathrm{Vu}$ et al. criterion}

$\mathrm{Vu}$ et al. [6] proposed a multiaxial criterion for high cycle fatigue based on invariants of macroscopic stress tensor (denoted as V-H-N criterion). The presence of $\mathrm{J}_{2 \text {,mean }}$ quantity allows capturing accurately effects of phase shift 
and frequency on fatigue limit of material under multiaxial loading. The prediction capacity of the criterion is tested on 119 iso-frequency axial-torsion experiments and some other more complex loadings: biaxial loading and asyn-chronous loading and the results show that the criterion is in good accordance with the experimental data. Under proportional loading, the assessment of the criterion can be carried out from an analytical solution. Under others loading cases, the numerical implementation of the criterion is very simple and can be easily integrated in a damage model or in a finite element code. By introducing the quantity $\mathrm{J}_{2 \text {,mean, }}$, the multiaxial fatigue endurance criterion is established as follows:

$$
f=\sqrt{\gamma_{1} J_{2}^{\prime}(t)^{2}+\gamma_{2} J_{2, \text { mean }}^{2}+\gamma_{3} I_{f}\left(I_{1, a}, I_{1, m}\right)} \leq \beta
$$

where $\gamma_{1}, \gamma_{2}, \gamma_{3}$ and $\beta$ are material parameters; $J_{2}^{\prime}(t)$ and $J_{2, \text { mean }}$ capture shear stress effect and phase shift effect. $J_{2}^{\prime}(t)$ is the second invariant of stress amplitude part defined from the deviator of the amplitude of the stress tensor $\underline{S}^{a}(t)$ and $J_{2, \text { mean }}$ is the mean value of $J^{\prime}{ }_{2}(t)$ during period $\mathrm{T}$ :

$$
\begin{gathered}
J_{2}^{\prime}(t)=\sqrt{\frac{1}{2} \underline{S}^{a}(t): \underline{\underline{S}}^{a}(t)} \\
J_{2, \text { mean }}=\frac{1}{T} \int_{0}^{T} J_{2}^{\prime}(t) d t
\end{gathered}
$$

$I_{f}\left(I_{1, a}, I_{1, m}\right)$ is a function of $\mathrm{I}_{1, \mathrm{a}}$ and $\mathrm{I}_{1, \mathrm{~m}}$ refeflecting resrespectively the effects of amplitude and mean value of the hydrostatic stress, in which $I_{1}(t)=\operatorname{tr}(\sigma)$ is the first invariant of the stress tensor.

\section{Implementation of multiaxial fatigue criteria in finite element code}

To apply multiaxial fatigue criteria for real structures subjected to complex loading, we need integrate the fatigue criteria into a finite element code. In this study, in order to implement the criteria, a combination of APDL (ANSYS Parametric Design Language) with ANSYS Workbench is carried out. The APDL scripting language is used to build the multiaxial fatigue criteria (Crossland, Dang Van, V-H-N) while the ANSYS Workbench Mechanical defines all other parts of the structure simulation: geometry, mesh, loads, boundary conditions and results processing.

The APDL commands for multiaxial fatigue criteria perform following steps:

- to record values of stress tensor components in function of time increment during one period

- to calculate the value of hydrostatic stress

- to calculate the value of the equivalent stresses according to Crossland, Dang Van and V-H-N criteria
- to visualize the fatigue analysis results in the form of contour maps

\section{Numerical example}

To implement and compare the fatigue criteria mentioned above, a simple cylindrical specimen was chosen as a test example. The dimensions of specimen (all in $\mathrm{mm}$ ) are shown in Fig. 1. The specimen is subjected to bending $\left(\mathrm{P}_{\mathrm{b}}\right)$ - torsion $\left(\mathrm{P}_{\mathrm{t}}\right)$ sinusoidal loading:

$$
P_{b}=P_{b a} \cdot \sin (2 \pi f t) \quad P_{t}=P_{t a} \cdot \sin (2 \pi f t-\delta)
$$

where $\mathrm{P}_{\mathrm{ba}}$ and $\mathrm{P}_{\mathrm{ta}}$ are the bending and torsion load amplitude, $\delta$ the phase shift angle, $t$ the time and $f$ the frequency. The considered material is hard steel with bending limit fatigue $\mathrm{f}_{-1}=313.9 \mathrm{MPa}$, torsion limit fatigue $\mathrm{t}_{-1}=196.2 \mathrm{MPa}$ and ultimate strength $\mathrm{R}_{\mathrm{m}}=680$ MPa.

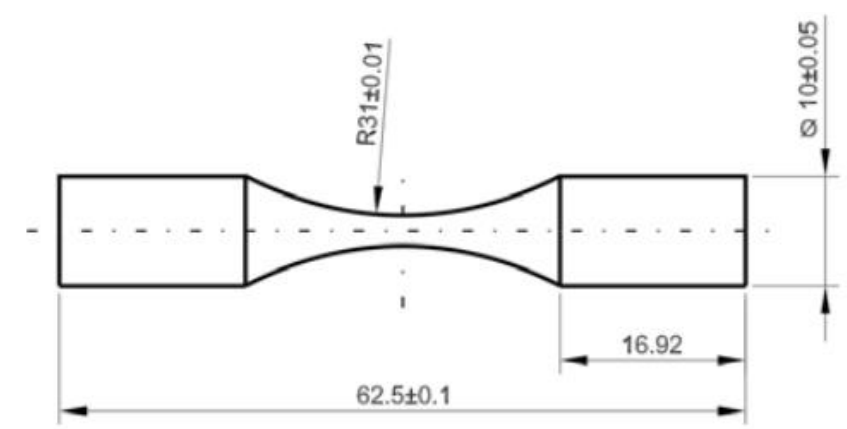

Figure 1. Specimen geometry.

To assess the predicting capacity of the fatigue criteria, comparison of the predicted fatigue limits against out-of-phase bending - torsion experimental results in the literature is carried out, an error index I is usually used:

$$
I=\left(\frac{\sigma_{e q}-\beta}{\beta}\right) \cdot 100 \%
$$

For the considered fatigue criteria and the assumed material properties, $\beta=t_{-1}=196.2(M P a)$ and the equivalent stresses of the criteria have the values as follows:

- Crossland criterion:

$\sigma_{e q, C}=\sqrt{J_{2, a}}+0.143 . \sigma_{H, \max }$

Dang Van criterion: $\sigma_{e q, D V}=\max \left[\tau(t)+0.375 . \sigma_{H}(t)\right]$

V-H-N criterion:

$\sigma_{e q, V}=\sqrt{0.65 J_{2}^{\prime}(t)^{2}+0.8636 J_{2, \text { mean }}^{2}+18\left(I_{1, a}+I_{1, m}\right)}$

The error indexes $I_{C}, I_{D V}, I_{V}$ refer respectively to the predicted results of Crossland, Dang Van and V-H-N criteria. Table 1 summarizes the prediction of criteria in some loading cases with different phase shift angle. The bending - torsion experimental results are collected from 
[1]. As shown in Table 1, the predictions of Crossland and Dang Van criteria are dangerous under $90^{\circ}$ out-ofphase loading case while the V-H-N criterion captures quite accurately the effect of phase shift including $90^{\circ}$ case.

Table 1. Out-of-phase bending-torsion fatigue limit data of hard steel specimen.

\begin{tabular}{|l|l|l|l|l|l|}
\hline 138.1 & 167.1 & 0 & -2.3 & 1.4 & -1.99 \\
\hline 140.4 & 169.9 & 30 & -2.5 & 0.24 & -1.01 \\
\hline 145.7 & 176.3 & 60 & -3.6 & 2.09 & 1.37 \\
\hline 258.0 & 129.0 & 90 & -17.8 & -16.83 & -3.19 \\
\hline
\end{tabular}

\begin{tabular}{|c|c|c|c|c|c|}
\hline $\begin{array}{c}\mathbf{P}_{\mathrm{ba}} \\
(\mathbf{M P a})\end{array}$ & $\begin{array}{c}\mathbf{P}_{\mathrm{ta}} \\
(\mathbf{M P a})\end{array}$ & $\boldsymbol{\delta}\left({ }^{\circ}\right)$ & $\begin{array}{c}\mathbf{I}_{\mathbf{C}} \\
(\mathbf{\%})\end{array}$ & $\begin{array}{c}\mathbf{I}_{\mathbf{D V}} \\
(\mathbf{\%})\end{array}$ & $\begin{array}{c}\mathbf{I}_{\mathbf{V}} \\
(\mathbf{\%})\end{array}$ \\
\hline
\end{tabular}
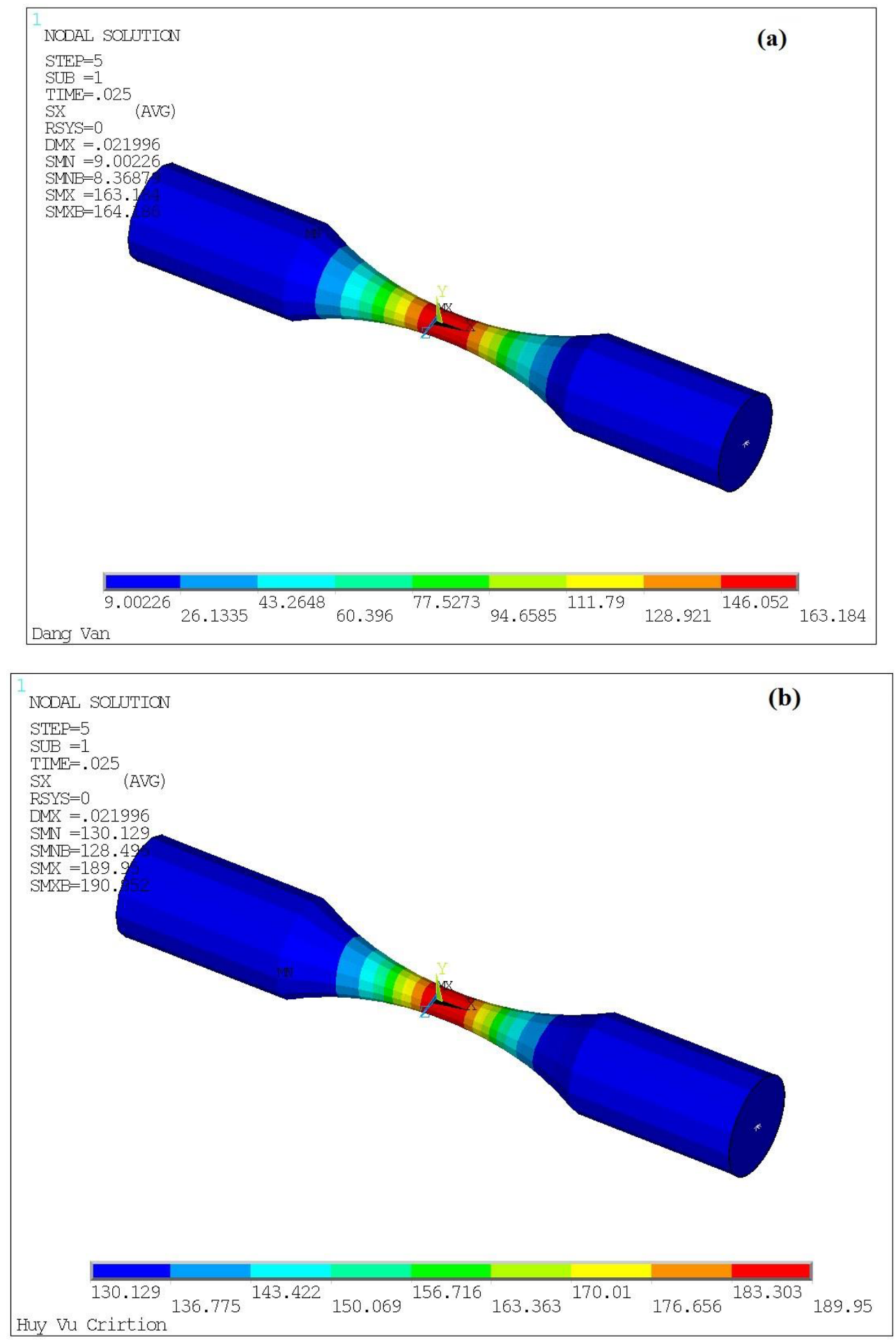

Figure 2. Field of equivalent stress (MPa) according to Dang Van (a) and V-H-N criteria (b). 
The contours of equivalent stress $(\mathrm{MPa})$ in the specimen according to Dang Van and V-H-N criteria are shown in Fig. 2, in which the variable SMX means maximal equivalent stress $(\mathrm{MPa})$. While the contour shapes of two criteria are quite similar, the values of SMX show the difference between two criteria $\left(\mathrm{SMX}_{\text {Dang }}\right.$ $\left.\mathrm{Van}=163.14 ; \mathrm{SMX}_{\mathrm{V}-\mathrm{H}-\mathrm{N}}=189.95\right)$.

\section{Conclusion}

The numerical implementation of multiaxial fatigue criteria in finite element code is carried out in this paper. Three fatigue criteria have been tested including Crossland, Dang Van and V-H-N criteria. The combination of APDL script with ANSYS Workbench Mechanical shows a good performance to integrate multiaxial criteria into finite element code. From the computational point of view, the criterion $\mathrm{V}-\mathrm{H}-\mathrm{N}$ has the same order of simplicity as the Crossland criterion. The implementation of $\mathrm{V}-\mathrm{H}-\mathrm{N}$ criterion may expand for more complex analyses such as variable amplitude fatigue loading.

\section{Acknowledgments}

This research is funded by Vietnam National Foundation for Science and Technology Development (NAFOSTED) under grant number 107.02-2014.25.

\section{References}

1. I. V. Papadopoulos, P. Davoli, C. Gorla, M. Filippini and A. Bernasconi, Int. J. Fatigue, 19(3), p. 219-235 (1997)

2. J. Papuga, Procedia Engineering, 66, p. 587-597 (2013)

3. M. Mrzyglod, A. P. Zielinski, J. Theor. Appl. Mech., 44(3), p. 691-712 (2006)

4. B. Crossland, Proceedings of the international conference on fatigue of metals, London, p. 138-149 (1956)

5. K. Dang Van, Thèse de Doctorat ès Sciences. Sci Tech de l'Armement, 47(3), p. 647-722 (1973)

6. Q. H. Vu, D. Halm, Y. Nadot, Int. J. Fatigue, 32, p. 1004-1014 (2010) 